\title{
A comprehensive methodology for implementation of Industry 4.0 in India using an approach of AHP- fuzzy- ELECTRE
}

\author{
Abhishek $^{1}$, Akash Tigga $^{2}$, Allen Steven Dungdung ${ }^{3}$, Dr. Saurabh Agrawal ${ }^{4}$ \\ \{abhishek.gautam1110@gmail.com ${ }^{1}$, akashtigga007@gmail.com ${ }^{2}$, allen09steven@gmail.com ${ }^{3}$, \\ agrawals.iit@gmail.com ${ }^{4}$ \} \\ Department of Mechanical Engineering, Delhi Technological University, Delhi, India ${ }^{1,2,3}$ \\ Assistant Professor, Department of Mechanical Engineering, Delhi Technological University, Delhi, \\ India $^{4}$
}

\begin{abstract}
The purpose of this study is to develop a comprehensive methodology for successfully implementing Industry 4.0 in India. The study highlights the barriers to Industry 4.0 in India and uses a combined AHP- fuzzy-ELECTRE approach for ranking the barriers against a set of criteria and creates a roadmap of the barriers. The study finds out that Infrastructure is the biggest barrier and stands at the first place; Investment stands at the second place; Technology comes at third; and Awareness, Lack of Standards and Data Security, and Legal Barrier are more or less of the same scale and come at fourth. The study can be used by the Indian industrial setup to further develop their own measures to counter these barriers in an efficient manner to make India Industry 4.0 ready.
\end{abstract}

Keywords: Industry 4.0, Barriers, AHP, fuzzy-ELECTRE;

\section{Introduction}

Industry 4.0, the fourth in the line of industrial revolutions, was first coined in 2011 in Germany [1]. It initially aimed at digitisation of industry, but over the time it has evolved into a novel research arena involving the use of various nodal technologies. It includes under its vast umbrella the technologies like Cyber-Physical Systems (CPS), Mass Customisation, Internet of Things (IoT), Industrial Internet, Internet of Services (IoS), Cloud Computing, Internet of Energy (IoE), Big Data, Data Mining and Data Analytics, Artificial Intelligence (AI), Augmented Reality (AR), Industrial 3D Printing, Block Chain [2]. Industry 4.0's implementation offers increased competitiveness and reduced risks via integration of business segments to the industry [3]. SAMARTH- Udyog Bharat 4.0 is the premier policy of Government of India to make India Industry 4.0 ready [4]. Major objectives of this study are to highlight the barriers for the implementation of Industry 4.0 in India and to develop a framework for comparative ranking analysis of these barriers and to propose a methodology to the industry by using a combination of Analytical Hierarchy Process (AHP) and the ranking 
of barriers by using the fuzzy-ELECTRE (Elimination Et Choix Traduisant la Realité) approach.

\section{Literature Review}

CGI [5] studied the business benefits of Industry 4.0 ranging from reduction in breakdowns and maintenance costs, greening of operations, improvement in inventory management. The challenges were also identified including lack of awareness, cybersecurity infrastructure, investments and standardisation.

Christian Schroder [6] studied the economic potential of Industry 4.0 by the cut down in production costs. It analysed the obstacles like availability of skilled labourers, infrastructure and legal framework.

Saurabh Agrawal et al. [7] used an AHP (Analytical Hierarchical Process) framework for identification of various criteria and then using the fuzzy TOPSIS for selection of best alternative based on these criteria.

Pravin Kumar et al. [8] used a fuzzy-ELECTRE (Elimination and Choice Expressing Reality) approach to compare the performance of various TSPs in Delhi working area.

\subsection{Barriers to Industry 4.0 in India}

2.1.1. Awareness: $\mathrm{PwC}$ carried out a survey on Industrial Internet in its Indian division and only $27 \%$ of respondents were aware of this advancement [9]. Additionally, Industry 3.0 also has not been fully implemented in India and therefore the awareness on Industry 4.0 is still at its early stage.

2.1.2. Infrastructure: $B C G$ reported $90 \%$ MSMEs in India have no access to the internet, in comparison China and USA were reported at $22 \%$ and $5 \%$ respectively. India's internet penetration stands at $13.5 \%$ and is ranked 127 among 201 countries and the fixed broadband speed stands at $34.01 \mathrm{Mbps}$ and is ranked at 72 among 175 countries [10]. Thus, India doesn't have a proper infrastructure in place which is the backbone for implementation of Industry 4.0.

2.1.3. Investment: The accessible credit gap in the MSME sector was estimated at INR 25.8 trillion which accounts for $95 \%$ of the total credit gap [11]. The modernisation of infrastructure and successful integration of networks requires huge investments and with the advent of LPG reforms attracting the investments is more difficult.

2.1.4. Technology: The complementary technologies for Industry 4.0 first have to be implemented successfully and these include 5G, Optical Fibre and Cloud Computing. The 5G is still at its nascent stage in India and the optical fibre kilometre per capita is one-tenth to that of China. Also, the nodal technologies demand a new skill pool thus creating new jobs and making redundant various previous jobs. Employment in the manufacturing sector is expected to decrease by $4 \%$ by 2025 and 2 million new jobs are expected to be created [12].

2.1.5. Lack of Standards and Data Security: India lacks a comprehensive standardisation ecosystem leading to different standards for different sectors and regulated by different ministries. The goods and services of India thus lag behind in domestic and international competition due to this. Industry 4.0 requires Cloud Computing and Storage for the integration of production units at every level. Thus the production lines are vulnerable to data breaches 
and hence cybersecurity framework needs to be strong enough. Cybersecurity boards were reported to be existant in only $23 \%$ of the organisations as per ASSOCHAM India and EY.

2.1.6. Legal Barriers: The legal issues arising out of the complex repository of data generated, stored and utilised pose a significant problem. Data usage by unauthorised thirdparty require effective control and regulation thus new laws must be put in place to manage the contracts between two parties, intervention in cases of breach and proper redressal mechanism. The liability of faulty products and services can't be easily attributed to a single stage and hence fault-finding methodologies must be put in place by establishing a nodal agency for taking action in case of disagreements. The data trade, imports and exports are regulated by different rules of different organisations, states and countries, impeding the free flow of data and thus the legality of this must be worked out between parties.

\section{Research Methodology}

In this study, the AHP approach is used to determine the weights of the criteria and this is followed by using the fuzzy-ELECTRE approach to rank the various barriers.

\subsection{Analytical Hierarchy Process (AHP)}

The AHP approach is a multi-criteria decision-making tool used to segregate a given problem into levels of hierarchy. The method used in this study was used by Saurabh Agrawal et al [7]. In this method, we develop a hierarchical structure using objective, criteria and alternatives respectively. Then we prepare a pair-wise comparison matrix using the criteria and assess the relative importance of one criterion over the other using an expert's opinion and Table 1 [13]. Then the weights are calculated for each criterion using the geometric mean and their pairwise comparison matrix. And then the consistency of judgement is evaluated using the largest Eigen Value, $\lambda_{\max }$. The deviation of $\lambda_{\max }$ from the number of elements (n) is used to calculate the consistency index (CI) using Eq. (1). And the Consistency Ratio (CR) is also calculated using the Random Index (RI) using Table 2 [13] and Eq. (2). If the CR is less than or equal to 0.1 then the matrix is acceptable for matrix order of 5 .

Table 1. Scale of Preferences

\begin{tabular}{ll}
\hline \multicolumn{1}{c}{ Preference Weights } & \multicolumn{1}{c}{ Definition } \\
\hline 1 & Equally Important \\
3 & Moderate \\
5 & Strong \\
7 & Very Strong \\
9 & Extreme \\
$2,4,6,8$ & Intermediate Values \\
Reciprocals & Reciprocals for opposite evaluation \\
\hline
\end{tabular}

$$
\mathrm{CI}(\text { consistency index })=\left(\chi_{\max }-\mathrm{n}\right) /(\mathrm{n}-1)
$$


Table 2: Random Index Values

\begin{tabular}{ccccccccccc}
\hline Number of Attributes (n) & 1 & 2 & 3 & 4 & 5 & 6 & 7 & 8 & 9 & 10 \\
\hline Random Index (RI) & 0 & 0 & 0.52 & 0.39 & 1.11 & 1.25 & 1.35 & 1.4 & 1.45 & 1.49 \\
\hline
\end{tabular}

\section{2. fuzzy-ELECTRE}

The ranking of the various barriers is done using the fuzzy-ELECTRE approach, in which the ELECTRE is integrated with fuzzy sets [14]. The method used in this study was used by Pravin Kumar et al. [8].

Step 1: Fuzzy Decision Matrix

The fuzzy decision matrix is prepared between barriers and criteria. For this first, the pairwise comparison matrix is prepared using Table 3 and experts' opinion. Then the linguistic terms are given their fuzzy numbers and Matrix 1 is obtained.

Table 3. Fuzzy No for Linguistic Terms

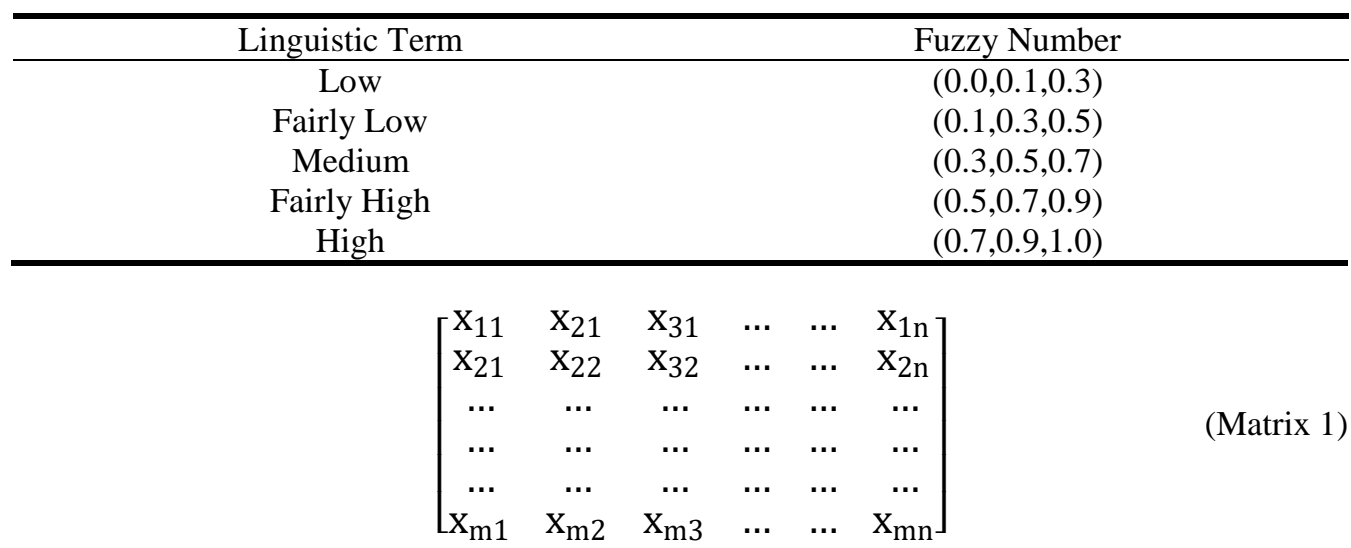

Step 2: Normalised Decision Matrix

Normalisation is used to ensure homogeneity in the decision matrix. For this, every criterion's maximum fuzzy number is found among all the alternatives and then every fuzzy number of the decision matrix is then divided by this number resulting in the normalised decision matrix.

Step 3: Weighted Decision Matrix

The weighted decision matrix is computed using Eq. (3).

$$
v_{i j}=\left(r_{i j}\right) \times\left(w_{j}\right)=\left(r_{i j}^{a}, r_{i j}^{b}, r_{i j}^{c}\right) \times\left(w_{j}^{a}, w_{j}^{b}, w_{j}^{c}\right)
$$

Step 4: Distance Matrices 
The distance between two fuzzy numbers is calculated using Eq. (4) [15,16]. Now the distances are found between barriers for each criterion separately.

$$
d(\tilde{A}, \tilde{B})=\sqrt{\sum_{k=1}^{3}\left(A_{k}-B_{k}\right)^{2}}
$$

Step 5: Concordance Criteria

The distance matrices are used to compute the concordance criteria matrix. We move cell wise in all the distance matrices and check for Eq. (5), if satisfied then the criterion number is noted. The same process is repeated for every cell and then all the criterion satisfying the logic are noted together in the barrier-barrier concordance criteria matrix.

$$
v_{x j} \geq v_{y j} \Leftrightarrow d\left(\max \left(v_{x j}, v_{y j}\right), v_{y j}\right) \geq d\left(\max \left(v_{x j}, v_{y j}\right), v_{x j}\right)
$$

Step 6: Concordance Matrix

Moving cell wise the weights of all the criteria in each cell are added together and the concordance matrix is thus computed.

Now the concordance level is computed by Eq. (6).

$$
\bar{c}=\sum_{x=1}^{m} \sum_{y=1}^{(m-1)} \frac{c_{x y}}{m(m-1)}
$$

Step 7: Boolean Concordance Matrix

Now moving cell wise in the concordance matrix if the value is less than concordance level we assign 0 and if greater then 1 .

Step 8: Discordance Matrix

We move cell wise in all the distance matrices and check for Eq. (7), if satisfied then we note the criterion number. Then we apply Eq. (8) to all these criteria for every cell of the discordance matrix.

$$
\begin{gathered}
v_{x j} \leq v_{y j} \Leftrightarrow d\left(\max \left(v_{x j}, v_{y j}\right), v_{y j}\right) \leq d\left(\max \left(v_{x j}, v_{y j}\right), v_{x j}\right) \\
\mathrm{d}_{\mathrm{xy}}=\frac{\max _{\mathrm{j} \epsilon \mathrm{J}}\left|\mathrm{v}_{\mathrm{xj}}-\mathrm{v}_{\mathrm{yj}}\right|}{\max _{\mathrm{j}}\left|\mathrm{v}_{\mathrm{xj}}-\mathrm{v}_{\mathrm{yj}}\right|}=\frac{\max _{\mathrm{j} \epsilon \mathrm{D}} \mathrm{D}\left|\mathrm{d}\left(\max \left(\mathrm{v}_{\mathrm{xj}}, \mathrm{v}_{\mathrm{yj}}\right), \mathrm{v}_{\mathrm{xj}}\right)\right|}{\max _{\mathrm{j}}\left|\mathrm{d}\left(\max \left(\mathrm{v}_{\mathrm{xj}}, \mathrm{v}_{\mathrm{yj}}\right), \mathrm{v}_{\mathrm{yj}}\right)\right|}
\end{gathered}
$$

Now the discordance level is computed by Eq. (8).

Step 9: Boolean Discordance Matrix

Now moving cell wise in the discordance matrix if the value is less than discordance level then we assign 1 and if greater then 0 .

Step 10: Global Matrix

Global matrix is computed by multiplying the boolean concordance matrix and boolean discordance matrix element to element.

Step 11: Ranking of Barriers

Barriers are ranked based on the global matrix, we move barrier wise and find the nondominant barriers for each. Based on the resulting table the barriers are ranked with respect to each other. 


\section{Case Illustration}

The barriers to Industry 4.0 in India are highlighted in this study using the past researches and studies. This was covered in the Literature Review section. Now the barriers are ranked using the Research Methodology section previously covered. First, the criteria are identified using the AHP approach.

\subsection{Economic Impact}

Although India being a labour-intensive country may have difficulty in reaping the economic benefits of the capital-intensive Industry 4.0, new jobs will be created, demand will be generated, supplies will increase and GDP will increase hence a virtuous cycle of the economy will be brought about making India a self-sufficient economy.

\subsection{Social Impact}

MSMEs contribute $28.9 \%$ to the national GDP and $51.25 \%$ of these are based in rural areas. Also, $20.37 \%$ of these are owned by women and $66.27 \%$ are owned by socially backward classes [17]. Thus socially this revolution holds the potential of making India egalitarian.

\subsection{Political Impact}

A few organisations may have access to top-notch technologies and thus control large sums of data. Thus concentrating the wealth and power in a few hands and degrading the present scenario further, changing the power equation of the world and creating a new world order [18].

\subsection{Stakeholder's Benefits}

Industry 4.0's stakeholders encompass a huge horizon from governments, industries and organisations to the consumers. A different sections of stakeholders may reap different benefits. Benefits to a section may even be prove detrimental to other stakeholders. Thus a balancing act may be required by the regulators.

\subsection{Sustainability}

The shift to a capital-intensive economy as a result of this revolution may not be sustainable for India [19]. Also, ecological and environmental issues arising out of this technology will have to be dealt with caution by the organisations [20]. Thus sustainable implementation of this revolution is required.

These criteria are taken into the application of fuzzy-ELECTRE. And the pair-wise comparison is made in Table 4. CR is found out to be 0.0939837 , RI is 1.11 for the order of 5 and $\mathrm{CI}$ is 0.08467 . Thus as it is less than 0.1 , the judgements are consistent. Thus we can proceed further.

\begin{tabular}{lllllll}
\hline Criteria & C1 & C2 & C3 & C4 & C5 & Weights \\
\hline
\end{tabular}




\begin{tabular}{lcccccc}
\hline Economic Impact (C1) & 1 & 4 & 8 & 3 & 5 & 0.477 \\
Social Impact (C2) & $1 / 4$ & 1 & 4 & $1 / 2$ & 3 & 0.148 \\
Political Impact (C3) & $1 / 8$ & $1 / 4$ & 1 & $1 / 5$ & $1 / 4$ & 0.038 \\
Stakeholder's Benefits (C4) & $1 / 3$ & 2 & 5 & 1 & 6 & 0.258 \\
Sustainability (C5) & $1 / 5$ & $1 / 3$ & 0 & $1 / 6$ & 1 & 0.079 \\
\hline
\end{tabular}

Table 4. Pair-wise Comparison of Criteria

Now the barriers are evaluated with respect to criteria with the help of an expert's opinion. For this, the criteria are taken as Awareness (B1), Infrastructure (B2), Technology (B3), Lack of Standards and Data Security (B5) and Legal Barriers (B6).

Now the fuzzy decision matrix is computed.

Table 5. Fuzzy Decision Matrix

\begin{tabular}{llllll}
\hline & \multicolumn{1}{c}{$\mathrm{C} 1$} & \multicolumn{1}{c}{$\mathrm{C} 2$} & \multicolumn{1}{c}{$\mathrm{C} 3$} & \multicolumn{1}{c}{$\mathrm{C} 4$} & \multicolumn{1}{c}{$\mathrm{C5}$} \\
\hline $\mathrm{B} 1$ & $\mathrm{FL}(0.1,0.3,0.5)$ & $\mathrm{FH}(0.5,0.7,0.9)$ & $\mathrm{FL}(0.1,0.3,0.5)$ & $\mathrm{H}(0.7,0.9,1)$ & $\mathrm{M}(0.3,0.5,0.7)$ \\
B2 & $\mathrm{H}(0.7,0.9,1)$ & $\mathrm{M}(0.3,0.5,0.7)$ & $\mathrm{L}(0,0.1,0.3)$ & $\mathrm{FH}(0.5,0.7,0.9)$ & $\mathrm{H}(0.7,0.9,1)$ \\
B3 & $\mathrm{H}(0.7,0.9,1)$ & $\mathrm{FH}(0.5,0.7,0.9)$ & $\mathrm{M}(0.3,0.5,0.7)$ & $\mathrm{FH}(0.5,0.7,0.9)$ & $\mathrm{L}(0,0.1,0.3)$ \\
B4 & $\mathrm{FH}(0.5,0.7,0.9)$ & $\mathrm{M}(0.3,0.5,0.7)$ & $\mathrm{L}(0,0.1,0.3)$ & $\mathrm{FH}(0.5,0.7,0.9)$ & $\mathrm{FH}(0.5,0.7,0.9)$ \\
B5 & $\mathrm{M}(0.3,0.5,0.7)$ & $\mathrm{FL}(0.1,0.3,0.5)$ & $\mathrm{M}(0.3,0.5,0.7)$ & $\mathrm{FH}(0.5,0.7,0.9)$ & $\mathrm{FH}(0.5,0.7,0.9)$ \\
B6 & $\mathrm{M}(0.3,0.5,0.7)$ & $\mathrm{FH}(0.5,0.7,0.9)$ & $\mathrm{H}(0.7,0.9,1)$ & $\mathrm{FH}(0.5,0.7,0.9)$ & $\mathrm{FL}(0.1,0.3,0.5)$ \\
\hline
\end{tabular}

Now the fuzzy normalised matrix is computed and then the fuzzy weighted matrix is computed.

Table 6. Fuzzy Weighted Matrix

\begin{tabular}{cccccc}
\hline & C1 & C2 & C3 & C4 & C5 \\
\hline B1 & $(0.05,0.14,0.24)$ & $(0.08,0.11,0.15)$ & $(0.00,0.01,0.02)$ & $(0.18,0.23,0.26)$ & $(0.02,0.04,0.06)$ \\
B2 & $(0.33,0.43,0.48)$ & $(0.05,0.08,0.11)$ & $(0.00,0.00,0.01)$ & $(0.13,0.18,0.23)$ & $(0.06,0.07,0.08)$ \\
B3 & $(0.33,0.43,0.48)$ & $(0.08,0.11,0.15)$ & $(0.01,0.02,0.03)$ & $(0.13,0.18,0.23)$ & $(0.00,0.01,0.02)$ \\
B4 & $(0.24,0.33,0.43)$ & $(0.05,0.08,0.11)$ & $(0.00,0.00,0.01)$ & $(0.13,0.18,0.23)$ & $(0.04,0.06,0.07)$ \\
B5 & $(0.14,0.24,0.33)$ & $(0.02,0.05,0.08)$ & $(0.01,0.02,0.03)$ & $(0.13,0.18,0.23)$ & $(0.04,0.06,0.07)$ \\
B6 & $(0.14,0.24,0.33)$ & $(0.08,0.11,0.15)$ & $(0.03,0.03,0.04)$ & $(0.13,0.18,0.23)$ & $(0.01,0.02,0.04)$ \\
\hline
\end{tabular}

The distance matrices are then computed using the fuzzy weighted matrix for each criterion. Then this matrix is used to evaluate the concordance criteria matrix. Then this matrix is used to compute the concordance matrix.

Table 7. Concordance Matrix

\begin{tabular}{ccccccc}
\hline & B1 & B2 & B3 & B4 & B5 & B6 \\
\hline B1 & - & 0.444 & 0.523 & 0.523 & 0.523 & 0.523 \\
B2 & 0.556 & - & 1 & 1 & 1 & 1
\end{tabular}




\begin{tabular}{lllcccc} 
B3 & 0.477 & 0 & - & 0.961 & 0.961 & 0.853 \\
B4 & 0.477 & 0 & 0.039 & - & 0.814 & 0.814 \\
B5 & 0.477 & 0 & 0.039 & 0.186 & - & 0.735 \\
B6 & 0.477 & 0 & 0.147 & 0.186 & 0.265 & - \\
\hline
\end{tabular}

The concordance matrix summation is found out to be 15 and the concordance level is 0.5 . Now comparing the concordance matrix cell wise with this value we get the boolean concordance matrix.

Then the discordance matrix is computed using the distance matrices.

Table 8. Discordance Matrix

\begin{tabular}{ccccccc}
\hline & B1 & B2 & B3 & B4 & B5 & B6 \\
\hline B1 & - & 1 & 1 & 1 & 1 & 1 \\
B2 & 0.121 & - & 0 & 0 & 0 & 0 \\
B3 & 0.108 & 1 & - & 0.398 & 0.37 & 0.082 \\
B4 & 0.173 & 1 & 1 & - & 0.345 & 0.345 \\
B5 & 0.684 & 1 & 1 & 1 & - & 1 \\
B6 & 0.467 & 1 & 1 & 1 & 0 & - \\
\hline
\end{tabular}

The discordance matrix summation is found out to be 18.093 and the discordance level is 0.6031. Now comparing the discordance matrix cell wise with this value, we get the boolean discordance matrix.

Now the global matrix is computed by using the boolean concordance matrix and boolean discordance matrix by multiplying them pair-wise.

Table 9. Global Matrix

\begin{tabular}{ccccccc}
\hline & A1 & A2 & A3 & A4 & A5 & A6 \\
\hline A1 & - & 0 & 0 & 0 & 0 & 0 \\
A2 & 1 & - & 1 & 1 & 1 & 1 \\
A3 & 0 & 0 & - & 1 & 1 & 1 \\
A4 & 0 & 0 & 0 & - & 1 & 1 \\
A5 & 0 & 0 & 0 & 0 & - & 0 \\
A6 & 0 & 0 & 0 & 0 & 0 & - \\
\hline
\end{tabular}

Now the dominance of every barrier over the other is identified using the global matrix. And the barriers are ranked.

Table 10. Ranking Matrix

\begin{tabular}{ccc}
\hline Alternatives & Non Dominant Alternatives & Rank \\
\hline
\end{tabular}




\begin{tabular}{ccc}
\hline A1 & - & 4 \\
A2 & $\mathrm{A} 1, \mathrm{~A} 3, \mathrm{~A} 4, \mathrm{~A} 5, \mathrm{~A} 6$ & 1 \\
$\mathrm{~A} 3$ & $\mathrm{~A} 4, \mathrm{~A} 5, \mathrm{~A} 6$ & 2 \\
$\mathrm{~A} 4$ & $\mathrm{~A} 5, \mathrm{~A} 6$ & 3 \\
A5 & - & 4 \\
A6 & - & 4 \\
\hline
\end{tabular}

Now using this ranking matrix, we have developed a dominance-based ranking scale and we can easily see the dominance relations between the barriers.

\section{Conclusion}

This study tried to develop a comprehensive methodology for highlighting the barriers to Industry 4.0 and ranking these barriers using the AHP and fuzzy-ELECTRE approach. It is found that for the ranking of the barriers, we need a variety of criteria, and here we use the AHP approach. Now the barriers are ranked by the fuzzy-ELECTRE approach. It outranks the non-dominant barriers and selects the dominant barriers over them.

The barriers highlighted are Awareness, Infrastructure, Investment, Technology, Lack of Standards and Data Security, and Legal Barriers. Using the fuzzy-ELECTRE approach, we find that Infrastructure outranks all the other barriers, followed by Investment, Technology, Awareness, Lack of Standards and Data Security, and Legal Barriers. Wherein Awareness, Lack of Standards and Data Security, and Legal Barriers are more or less of the same scale.

Therefore we have developed a comprehensive methodology in this study, and the industry can benefit from the roadmap developed on the basis of precedence of the barriers. Further, the industrial setup can devise their own step-wise measures to implement Industry 4.0 successfully.

\section{References}

[1] BMBF-Internetredaktion (2018). Industrie 4.0 - BMBF. Bundesministerium für Bildung und Forschung - BMBF. Available at: https://www.bmbf.de/de/zukunftsprojekt-industrie-4-0848.html.

[2] Dr. Mirjana Stankovic, Gupta, R. and Dr. Juan E. Figueroa (n.d.). INDUSTRY 4.0 OPPORTUNITIES BEHIND THE CHALLENGE Background Paper 2 ACKNOWLEDGEMENTS. Available at: https://www.unido.org/sites/default/files/files/201711/UNIDO\%20Background\%20Paper\%20on\%20Industry\%204.0_27112017.pdf.

[3] Industry 4.0 Challenges and solutions for the digital transformation and use of exponential technologies. (n.d.).

Available

at: https://www2.deloitte.com/content/dam/Deloitte/ch/Documents/manufacturing/ch-enmanufacturing-industry-4-0-24102014.pdf.

[4] Samarthudyog-i40.in. (2019). SAMARTH Udyog. Available at:
https://www.samarthudyog-i40.in/. 
[5] Cgi.com. (2019). Industry 4.0: Making your business more competitive. Available at: https://www.cgi.com/en/white-paper/Industry-4-making-your-business-more-competitive.

[6] Christian Schröder The Challenges of Industry 4.0 for Small and Medium-sized Enterprises a good society - social democracy \# 2017 plus. (n.d.). Available at: https://library.fes.de/pdf-files/wiso/12683.pdf.

[7] Agrawal, S., Singh, R.K. and Murtaza, Q. (2016). Disposition decisions in reverse logistics by using AHP-fuzzy TOPSIS approach. Journal of Modelling in Management, 11(4), pp.932948.

[8] Kumar, P., Singh, R.K. and Kharab, K. (2017). A comparative analysis of operational performance of Cellular Mobile Telephone Service Providers in the Delhi working area using an approach of fuzzy ELECTRE. Applied Soft Computing, 59, pp.438-447.

[9] Rumpenhorst, F. (2016). Industry 4.0 building your digital enterprise april 2016. Available at: https://www.pwc.com/gx/en/industries/industries-4.0/landing-page/industry-4.0building-your-digital-enterprise-april-2016.pdf.

[10] Sharma, M. (2016). India's Tryst with 5G | Institute for Defence Studies and Analyses. Idsa.in. Available at: https://idsa.in/issuebrief/india-tryst-with-5g-msharma-200319.

[11] Financing India's MSMEs Estimation of Debt Requirement of MSMEs in India. (2018). Available at: https://www.ifc.org/wps/wcm/connect/dcf9d09d-68ad-4e54-b9b7$614 \mathrm{c} 143735 \mathrm{fb} /$ Financing+India\%E2\%80\%99s+MSMEs+-

+Estimation+of+Debt+Requirement+of+MSMEs+in+India.pdf?MOD=AJPERES\&CVID=my 3 Cmzl.

[12] Fitsilis, P., Tsoutsa, P. and Gerogiannis, V. (2018). INDUSTRY 4.0: REQUIRED PERSONNEL COMPETENCES. Available at: https://stumejournals.com/journals/i4/2018/3/130.full.pdf.

[13] Saaty, R.W. (1987). The analytic hierarchy process-what it is and how it is used. Mathematical Modelling, 9(3-5), pp.161-176. Available at: https://www.sciencedirect.com/science/article/pii/0270025587904738.

[14] Hatami-Marbini, A., Tavana, M., Moradi, M. and Kangi, F. (2013). A fuzzy group Electre method for safety and health assessment in hazardous waste recycling facilities. Safety Science, 51(1), pp.414-426. Available at: https://www.sciencedirect.com/science/article/pii/S0925753512002196.

[15] Chen, C.-T. (2000). Extensions of the TOPSIS for group decision-making under fuzzy environment. Fuzzy Sets and Systems, 114(1), pp.1-9. Available at: https://www.sciencedirect.com/science/article/pii/S0165011497003771.

[16] Li, D. (2004). Fuzzy linear programming technique for multiattribute group decision making in fuzzy environments. Information Sciences, [online] 158, pp.263-275. Available at: https://www.sciencedirect.com/science/article/pii/S0020025503002019.

[17] Bhavan, U. (2018). Ministry of Micro, Small and Medium Enterprises. Available at: https://msme.gov.in/sites/default/files/Annualrprt.pdf.

[18] Benioff, M. (2017). 4 ways to close the inequality gap in the Fourth Industrial Revolution. [online] World Economic Forum. Available at: https://www.weforum.org/agenda/2017/01/4-ways-to-close-the-inequality-gap-in-the-fourthindustrial-revolution.

[19] Maresova, P., Soukal, I., Svobodova, L., Hedvicakova, M., Javanmardi, E., Selamat, A. and Krejcar, O. (2018). Consequences of Industry 4.0 in Business and Economics. Economies, 6(3), p.46. Available at: https://www.mdpi.com/2227-7099/6/3/46. 
[20] M, G. and Pessl E (2016). ANALYSIS OF ENVIRONMENTAL POTENTIAL BY IMPLEMENTING INDUSTRY 4.0. Industry 4.0, 1(2), pp.141-144. Available at: https://stumejournals.com/journals/i4/2016/2/141. 